\title{
Prevalence and distribution of Aggregatibacter actinomycetemcomitans and its $c d t B$ gene in subgingival plaque of Chinese periodontitis patients
}

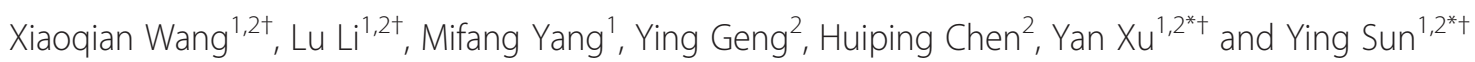

\begin{abstract}
Background: Aggregatibacter actinomycetemcomitans (A.actinomycetemcomitans) is an important periodontal pathogen that can participate in periodontitis and other non-oral infections. The cytolethal distending toxin (Cdt) is among the virulence factors produced by this bacterium. This study was to elucidate the distribution of A.actinomycetemcomitans and the prevalence of its $c d t B$ gene in Chinese subjects.

Methods: A total of 255 subgingival samples were obtained from 30 subjects. Samples were collected from periodontal healthy sites as well as shallow, moderate and deep pockets. The absolute quantity of A.actinomycetemcomitans and cdtB gene were determined by real-time polymerase chain reaction.

Results: A.actinomycetemcomitans was detected in 92 of 105 (87.6\%) samples of aggressive periodontitis (AgP) patients, in 73 of 79 (92.4\%) samples of chronic periodontitis ( CP) patients and in 5 of 71 (7.0\%) samples of periodontal healthy subjects. The cdtB gene was detected in 72 sites (78.3\%) with AgP infected with A.actinomycetemcomitans, 54 sites (74.0\%) with CP infected with A.actinomycetemcomitans and none in healthy sites infected with A.actinomycetemcomitans. In addition, quantity of A.actinomycetemcomitans and $c d t$ gene in samples from deep pockets were significant larger than moderate, shallow and healthy sites $(P<0.05)$. In comparison to $C P$, AgP patients were infected with increased numbers of $c d t$ genotype in deep pockets $(P<0.05)$.

Conclusion: This study suggests that the $c d t B$ gene are prevalent in A.actinomycetemcomitans, and the distribution of $c d t$ genotype strain may be correlated with $\mathrm{AgP}$ and serious periodontal inflammation.
\end{abstract}

Keywords: Aggregatibacter actinomycetemcomitans, Cytolethal distending toxin, Subgingival plaque, Real-time PCR

\section{Background}

Periodontitis is a chronic inflammatory disease leading to the loss of periodontal tissues, which is highly prevalent and is the major cause of tooth loss in adults. Aggressive periodontitis ( $\mathrm{AgP})$ is characterized with rapid development and serious bone resorption, generally affects younger patients than does the chronic form.

* Correspondence: yanxu@njmu.edu.cn; ebolasun@njmu.edu.cn

${ }^{\dagger}$ Equal contributors

'Laboratory of Oral Infection and Immunology, Institute of Stomatology, Nanjing Medical University, Nanjing, Jiang Su, China

${ }^{2}$ Department of Periodontology, College of Stomatology, Nanjing Medical University, Nanjing, Jiang Su, China
A.actinomycetemcomitans is a Gram-negative, non motile rod, facultative anaerobic and commensal bacterium, which has long been strongly associated with AgP and may also contribute to chronic periodontitis (CP). Apart from oral infection, this bacterium has also been responsible for some systemic infectious diseases, such as endocarditic, meningitis, osteomyelitis, glomerulonephritis and arthritis [1].

This microorganism expresses several potential virulence factors that are involved in the colonization in oral cavity, inhibition of regeneration of periodontal tissues and interference with host defense mechanisms. In 1998, Ohguchi [1] revealed that A.actinomycetemcomitans could produce cytolethal distending toxin (CDT), which was secreted into 
the bacterial culture supernatant. It is clear that CDT is encoded by three genes designated $c d t A, c d t B$, and $c d t C$, which are arranged as an apparent operon. These three genes specify three polypeptides designated $\mathrm{CdtA}, \mathrm{CdtB}$ and $\mathrm{CdtC}$ with apparent molecular masses of 28,32 and $20 \mathrm{kDa}$ respectively, which form a heterotrimeric holotoxin [2-5]. CdtA and CdtC are necessary for the secretion of the toxin, while $\mathrm{CdtB}$ is responsible for the biologic activity [6]. $\mathrm{CdtB}$ has a sequence homology with mammalian DNase I, indicating a critical role for nuclease activity in host parasite interactions [7].

Among periodontal pathogenic bacteria, A.actinomycetemcomitans is the unique bacterium that can produce CDT. Accumulating evidences show that CDT is associated with the persistence of infection in animal models [7], increased expression of RANKL (receptor activation of nuclear factor- $\mathrm{\kappa} B$ ligand) and the consequent osteoclastogenesis [3]. There was report showing that $c d t A B C$ was absent [8] in A.actinomycetemcomitans isolated in Japan [9], but Kawamoto confirmed that $c d t A B C$ was frequently found in the genome of A.actinomycetemcomitans [10].

Till now, there have been few reports on the prevalence of $c d t$ genotype strain of A.actinomycetemcomitans in Chinese periodontitis patients. Accumulating evidences show that CDT is associated with the persistence of infection in animal models [7], increased expression of RANKL (receptor activation of nuclear factor- $\mathrm{KB}$ ligand) and the consequent osteoclastogenesis [3]. The association of CDT genetic diversity within A.actinomycetemcomitans should be better evaluated. In this study, we detected the distribution of A.actinomycetemcomitans and the prevalence of its putative virulence factor CDT encoding gene $c d t \mathrm{~B}$ in subgingival plaque obtained from Chinese patients suffering from $\mathrm{CP}$ and $\mathrm{AgP}$ by real-time PCR, to evaluate the association of A.actinomycetemcomitans CDT genetic diversity and clinical features.

\section{Methods}

\section{Subjects}

This study was approved by the Ethical Committee of Stomatological Hospital affiliated to Nanjing Medical University, Nanjing, China. The purposes and procedures of the study were explained and informed consents were obtained from all recruits.

Participants included in the present study were recruited at the Stomatological Hospital affiliated to Nanjing Medical University, from December 2008 to March 2009. 10 CP patients, $10 \mathrm{AgP}$ patients and 10 healthy subjects were recruited in this study.

The criteria for patient inclusion were as follows: (i) ethnic Han and 40 years old; (ii) no history of periodontal therapy; (iii) no systemic antibiotics or anti-inflammatory drugs taken within 3 months; (iv) healthy systemic conditions; (v) no pregnancy, and (vi) were not current users of tobacco products or nicotine replacement medication [10]. The periodontal healthy subjects had no sites with probing depth (PD) $>3 \mathrm{~mm}$ or clinical attachment loss $(\mathrm{CAL})>1 \mathrm{~mm}$, and no more than $10 \%$ of sites with bleeding on probing (BOP).The diagnoses of $\mathrm{CP}$ and $\mathrm{AgP}$ were made based on criteria defined at the workshop sponsored by the American Academy of Periodontology (AAP) in 1999 [11-13].

Sample sites were classified as shallow, moderate or deep according to the levels of PD and CAL. The level of PD was about $3 \mathrm{~mm}$ or the level of CAL was $1-2 \mathrm{~mm}$ in shallow group; and 4-6 $\mathrm{mm}$ of PD or 3-4 $\mathrm{mm}$ of CAL in moderate group. In deep group, the level of PD was over $6 \mathrm{~mm}$ or CAL $\geq 5 \mathrm{~mm}$ [12].

\section{Clinical measurements}

Before sampling, a complete periodontal examination was conducted to record clinical periodontal parameters by using FP32 probe (Florida probe, USA), including PD, CAL and BOP. All measurements were performed by a calibrated examiner. To avoid any contaminations that might result from bleeding on probing, clinical probing and measurement were carried out at least 7 days in advance of bacteria sampling [14].

\section{Sampling of subginginval bacteria plaque}

8-10 samples were taken from shallow, moderate and deep sites of each enrolled patients suffering from $\mathrm{CP}$ and AgP, as well as from gingival sulci of healthy controls. After careful removal of supragingival plaque deposits, the sampling site was isolated with cotton rolls and gently air-dried. Then, a $30 \#$ paper point $[15,16]$ was inserted into the pockets/gingival sulci and left in place for 30s. The paper point from each sampling site was immediately placed into an empty $1.5 \mathrm{ml}$ microfuge tube. Samples for PCR analysis were stored at $-80^{\circ} \mathrm{C}$.

\section{Positive control bacterial strains}

A.actinomycetemcomitans ATCC 29522, ATCC 29523, ATCC 24523 were grown anaerobically $\left(75 \% \mathrm{~N}_{2}, 10 \%\right.$ $\mathrm{CO}_{2}, 15 \% \mathrm{H}_{2}$ ) at $37^{\circ} \mathrm{C}$ on $5 \%$ sheep blood agar plates (Oxoid, UK) enriched with haemin $(5 \mathrm{mg} / \mathrm{l})$ and menadione $(1 \mathrm{mg} / \mathrm{l})$ for $3-5$ days, and then inoculated into brain heart infusion broth until grown to the late logarithmic phase of growth. The bacteria were harvested by centrifugation, washed in PBS, and re-suspended at a concentration with optical density at $690 \mathrm{~nm}$ of 1 , corresponding to approximately $1 \times 10^{8}$ colony-forming units $(\mathrm{CFU}) / \mathrm{ml}[17]$.

\section{Oligonucleotide primers and TaqMan probes}

Identification of conserved regions was done by multiple sequence alignment with ClustalW software based on 
the published $16 \mathrm{~S}$ rDNA and $c d t B$ sequences. The fluorescent dyes at the $5^{\prime}$ and $3^{\prime}$ ends of the probe were FAM (6-carboxyfluorescein; reporter) and TAMRA (6carboxytetramethylrhodamine; quencher), respectively. All primers and probes were checked for possible crosshybridization with bacterial genes using the database similarity search program BLAST. Primers and probes used for quantification of $A$ actinomycetemcomitans $16 S$ rDNA and $c d t$ gene were shown in Table 1.

\section{Standard curves construction}

In order to establish the quantitative assay, plasmids containing the target sequences of A.actinomycetemcomitans $16 \mathrm{~S}$ rDNA and $c d t$ gene were cloned using the pMD 19 T-Vector (Takara, Japan). PCR products for $A$. actinomycetemcomitans $16 \mathrm{~S}$ rDNA and $c d t$ gene were inserted into plasmid vectors respectively, and the recombinant vectors were transformed into $E$. coli. Then, the plasmids were purified with Mini BEST Plasmid Purification Kit (Takara, Japan). The purified plasmids were quantified by spectrophotometry. Standard curves were constructed by using serial diluted purified plasmids with predetermined concentrations on the basis of the linear relationship between the Ct and the logarithm of the starting gene amount. Sensitivity of the developed real-time PCR assay was evaluated by using $10^{7}-10^{\circ}$ plasmid copies of $A$. actinomycetemcomitans and $c d t B$ gene (data not shown), limit of approximately 10 cells was established in the PCR reaction mixture.

\section{DNA extraction and Real-time PCR}

Each sample was diluted in $500 \mu \mathrm{l}$ distilled water, dispersed in vortex for $1 \mathrm{~min}$, took out the paper points before DNA extraction. Then, DNA was purified by the Mini BEST Bacteria Purification Kit (Takara, Japan), and eluted in $60 \mu$ l elution buffer.

TaqMan Universal PCR Master Mix (Applied Biosystems, USA) was used for PCR analysis. The final concentration was used in a total volume of $10 \mu \mathrm{l}$ contained $5 \mu \mathrm{l}$ of $2 \times$ Master Mix, $3 \mu \mathrm{l}$ of DNA template, $0.9 \mathrm{mM}$ of each primer and $0.25 \mathrm{mM}$ of probe. Real-time PCR

Table 1 Primers and TaqMan probes sequences

\begin{tabular}{ccc}
\hline Primer & Sequence & Products size \\
\hline Aa-F & GCTGGTCTGAGAGGATGGC & \\
Aa- $\mathrm{R}$ & CGAAAGAACTTACAACCCGA & $153 \mathrm{bp}$ \\
Aa-P & CCTACGGGAGGCAGCAGTGG & \\
$c d t B-\mathrm{F}$ & ATTCTTCTGTGCTTCAATCTCG & \\
$c d t B-\mathrm{R}$ & GGTGATGATGGTGATGAGGTAA & $151 \mathrm{bp}$ \\
$c d t B-P$ & CACAGGTGGTTCTGATGCGGTAA & \\
\hline
\end{tabular}

$A a-\mathrm{F}, A a-\mathrm{R}$ and $A a-\mathrm{P}$ stand for primers and TaqMan probe for $A$. actinomycetemcomitans $16 \mathrm{~s}$ rDNA; $c d t B-\mathrm{F}, c d t B-\mathrm{R}$ and $c d t B-\mathrm{P}$ stand for primers and TaqMan probe for A.actinomycetemcomitans $c d t B$. was carried out in duplicates in ABI 7900 HT system (Applied Biosystems, USA) with the following sequence: $2 \mathrm{~min}$ at $50^{\circ} \mathrm{C}, 10 \mathrm{~min}$ at $95^{\circ} \mathrm{C}$ and 40 cycles of $15 \mathrm{~s}$ at $95^{\circ} \mathrm{C}$ and $1 \mathrm{~min}$ at $60^{\circ} \mathrm{C}$.

\section{Statistical analysis}

Descriptive analysis was performed for all variables. Quantitative variables were described by mean values, standard deviations, as well as minimum and maximum values. Qualitative variables were described by absolute and relative frequencies. Comparisons were made between groups (AgP, CP and healthy subjects) for independent variables (PD) by applying analysis of variance (ANOVA). All tests were performed using SPSS for Windows Release 12.0 (USA) and P values less than 0.05 were considered significant.

\section{Results}

Clinical analysis

We analyzed plaque samples collected from 30 subjects following the protocols described above. This study consisted of 255 subgingival plaque samples, which were collected from $10 \mathrm{AgP}$ patients, $10 \mathrm{CP}$ patients and 10 periodontal healthy subjects. The study population had no previous history of smoking or periodontal treatment.

The mean values of PD, CAL and BOP (\%) of all sampling sites were shown in Table 2 . These results revealed that there were no statistical differences in these parameters between $\mathrm{CP}$ and $\mathrm{AgP}$ groups, while there were significant differences between either $\mathrm{CP}$ group or AgP group and periodontal healthy subjects.

\section{Occurrence and distribution of A.actinomycetemcomitans}

Using real-time PCR, we examined 255 subgingival plaque samples to evaluate the levels of A.actinomycetemcomitans in different status of periodontal sites. Among all of the 255 subgingival samples, A.actinomycetemcomitans was

Table 2 Clinical characteristics of periodontitis patients and healthy controls

\begin{tabular}{cccc}
\hline & $\mathbf{H}$ & $\mathbf{C P}$ & AgP \\
\hline Subjects & 10 & 10 & 10 \\
Sampling sites & 71 & 79 & 105 \\
Age(years-old, mean \pm SD) & $27.5 \pm 2.1$ & $32.5 \pm 1.8$ & $29.7 \pm 2.1$ \\
Gender(male/female) & $5 / 5$ & $5 / 5$ & $5 / 5$ \\
PD(mm, mean \pm SD) & $2.4 \pm 0.8$ & $4.1 \pm 2.0 *$ & $4.9 \pm 1.9 *$ \\
CAL(mm, mean \pm SD) & 0 & $4.8 \pm 2.0 *$ & $4.5 \pm 1.9 *$ \\
BOP(\%, mean \pm SD) & $15.8 \pm 0.9$ & $30.8 \pm 5.5 *$ & $30.6 \pm 7.2 *$ \\
\hline
\end{tabular}

$\mathrm{AgP}, \mathrm{CP}$ and $\mathrm{H}$ stand for aggressive periodontitis, chronic periodontitis and periodontal healthy, respectively.

The mean probing depth, clinical attachment loss and bleeding on probing (\%) were recorded in 255 sampling sites from 30 patients. * There were significant differences for mean probing depth, clinical attachment loss and bleeding on probing (\%) between AgP or $\mathrm{CP}$ and $\mathrm{H}(\mathrm{P}<0.05)$, but there was no significant difference between $\mathrm{AgP}$ and $\mathrm{CP}$. 
detected from 170 (66.7\%) samples. Only 5 samples (7.0\%) out of the 71 subgingival samples from the periodontally healthy individuals were A.actinomycetemcomitans $16 \mathrm{~s}$ rDNA positive (Table 3). 73 of the 79 subgingival plaque samples (92.4\%) from CP patients were A.actinomycetemcomitans $16 \mathrm{~s}$ rDNA positive. And among the 105 subgingival plaque samples from AgP patients, 92 (87.6\%) were A.actinomycetemcomitans $16 \mathrm{~s}$ rDNA positive. There was no statistical difference of A.actinomycetemcomitans positive rates between CP (92.4\%) and AgP (87.6\%) (P > 0.05) (Table 3).

Mean log-transformed numbers of A.actinomycetemcomitans $16 \mathrm{~s}$ rDNA in healthy subjects, $\mathrm{CP}$ patients and AgP patients were $0.8 \pm 0.5,2.1 \pm 0.9$ and $2.3 \pm 1.1$ (Table 3), respectively. Higher numbers of A.actinomycetemcomitans were detected in samples from periodontitis sites in contrast to those from healthy subjects $(\mathrm{P}<0.05)$. However, there were no significant differences between these two periodontitis groups $(\mathrm{P}>0.05)$.

\section{Prevalence and distribution of A.actinomycetemcomitans cdt $B$ gene}

Out of 255 subgingival samples, A.actinomycetemcomitans $c d t B$ was detected in $126(49.4 \%)$ samples. In the 71 subgingival samples from periodontal healthy individuals, none of the samples were $c d t B$ positive (Table 3 ). While 54 of the 73 (74.0\%) A.actinomycetemcomitans positive subgingival plaque samples from $C P$ patients were $c d t B$ positive. Among the 92 A.actinomycetemcomitans positive subgingival plaque samples from AgP patients, 72 (78.3\%) samples were A.actinomycetemcomitans $c d t B$ positive. There was no statistical difference for the A.actinomycetemcomitans $c d t B$ positive rates between $\mathrm{CP}(74.0 \%)$ and AgP (78.4\%) $(\mathrm{P}>0.05)$. None of the A.actinomycetemcomitans $16 \mathrm{~s}$ rDNA negative samples were positive for $c d t B$.

Table 3 Prevalence of A.actinomycetemcomitans and cdt in all sampling sites

\begin{tabular}{cccc}
\hline & AgP & CP & H \\
\hline Total & 105 & 79 & 71 \\
$A a(+)$ & 92 & 73 & 5 \\
$A a(+) / T o t a l(\%)$ & 87.6 & 92.4 & 7.0 \\
$c d t(+)$ & 72 & 54 & 0 \\
$c d t(+) / A a(+)(\%)$ & 78.3 & 74.0 & 0 \\
Quantity-Aa & $2.3 \pm 1.1^{*}$ & $2.1 \pm 0.9^{*}$ & $0.8 \pm 0.5$ \\
Quantity-cdt & $1.6 \pm 0.8^{* *}$ & $1.3 \pm 0.8^{* * *}$ & $0.4 \pm 0.3$ \\
\hline
\end{tabular}

$A a, \mathrm{AgP}, \mathrm{CP}$ and $\mathrm{H}$ stand for A.actinomycetemcomitans, aggressive periodontitis samples, chronic periodontitis samples and periodontal healthy samples, respectively.

*There were significant differences for quantity of A.actinomycetemcomitans between $\mathrm{AgP}$ or $\mathrm{CP}$ and $\mathrm{H}(\mathrm{P}<0.05)$ and no significant differences between $\mathrm{AgP}$ and $\mathrm{CP}(\mathrm{P}>0.05)$. ${ }^{* *}$ Quantity of $c d t$ genotype of A.actinomycetemcomitans from AgP samples were significantly higher than that of $C P$ and $H(P<0.05)$. ${ }^{* * *}$ Quantity of $c d t$ genotype of A.actinomycetemcomitans from $\mathrm{CP}$ samples were significantly higher than $\mathrm{H}(\mathrm{P}<0.05)$.
Levels of $c d t B$ gene were also detected in 255 samples. Mean log-transformed numbers of $c d t B$ in CP and AgP were $1.3 \pm 0.8$ and $1.6 \pm 0.8$ (Table 3). Samples of AgP group showed the higher numbers of $c d t B$ genotype $A$. actinomycetemcomitans contrast to $\mathrm{CP}$ group and periodontal healthy subjects $(\mathrm{P}<0.05)$.

\section{Association of A.actinomycetemcomitans and cdt distribution with different periodontal status}

Mean log-transformed numbers of A.actinomycetemcomitans and $c d t B$ gene in shallow, moderate and deep pockets were $1.8 \pm 0.9,2.2 \pm 0.8,3.1 \pm 1.2$ and $1.3 \pm 0.8$, $1.5 \pm 0.8,2.1 \pm 1.1$ (Table 4), respectively. Higher quantity of A.actinomycetemcomitans and $c d t B$ gene in deep periodontal pockets were detected than moderate and shallow pockets $(\mathrm{P}<0.05)$.

With respect to the various periodontal statuses, mean log-transformed numbers of A.actinomycetemcomitans and $c d t B$ gene from $\mathrm{CP}$ and $\mathrm{AgP}$ in shallow, moderate and deep pockets were shown in Figure 1 respectively. The quantity of A.actinomycetemcomitans and $c d t B$ gene in deep periodontal pockets from AgP was higher than CP $(\mathrm{P}<0.05)$.

\section{Discussion}

This research we employed TaqMan real-time PCR to direct target quantification A.actinomycetemcomitans and $c d t \mathrm{~B}$ gene in different severity of periodontitis sites of AgP or CP patients.and it is effective for detecting pathogen species that are extremely difficult to culture. Therefore, we chose different periodontal sites as targets to explore the occurrence and quantity of A.actinomycetemcomitans and its CDT encoding gene in Chinese subjects and different periodontal status. A.actinomycetemcomitans might not be present in all oral sites in an untreated periodontitis patient [18]. Taking subgingival samples from all teeth would be the most reliable way to detect A.actinomycetemcomitans. However, this method is money-consuming and time-consuming which is not suitable to be used in daily practice. Sampling from the deepest pocket of each quadrant has been demonstrated

Table 4 Prevalence and distribution of $A$. actinomycetemcomitans and $c d t$ in periodontitis sampling sites by probing depth

\begin{tabular}{cccc}
\hline & Shallow & Moderate & Deep \\
\hline Total & 100 & 49 & 35 \\
Quantity-Aa & $1.8 \pm 0.9$ & $2.2 \pm 0.8^{*}$ & $3.1 \pm 1.2^{* *}$ \\
Quantity-cdt & $1.3 \pm 0.8$ & $1.5 \pm 0.8$ & $2.1 \pm 1.1^{* *}$ \\
\hline
\end{tabular}

*Mean log-transformed numbers of A.actinomycetemcomitans 16 s rDNA from moderate pockets samples were significantly higher than that from shallow pockets $(P<0.05)$.

**Mean log-transformed numbers of A.actinomycetemcomitans $16 \mathrm{~s}$ rDNA and $c d t$ genotype of A.actinomycetemcomitans from deep pockets samples were significantly higher than that from moderate and shallow pockets $(P<0.05)$. 


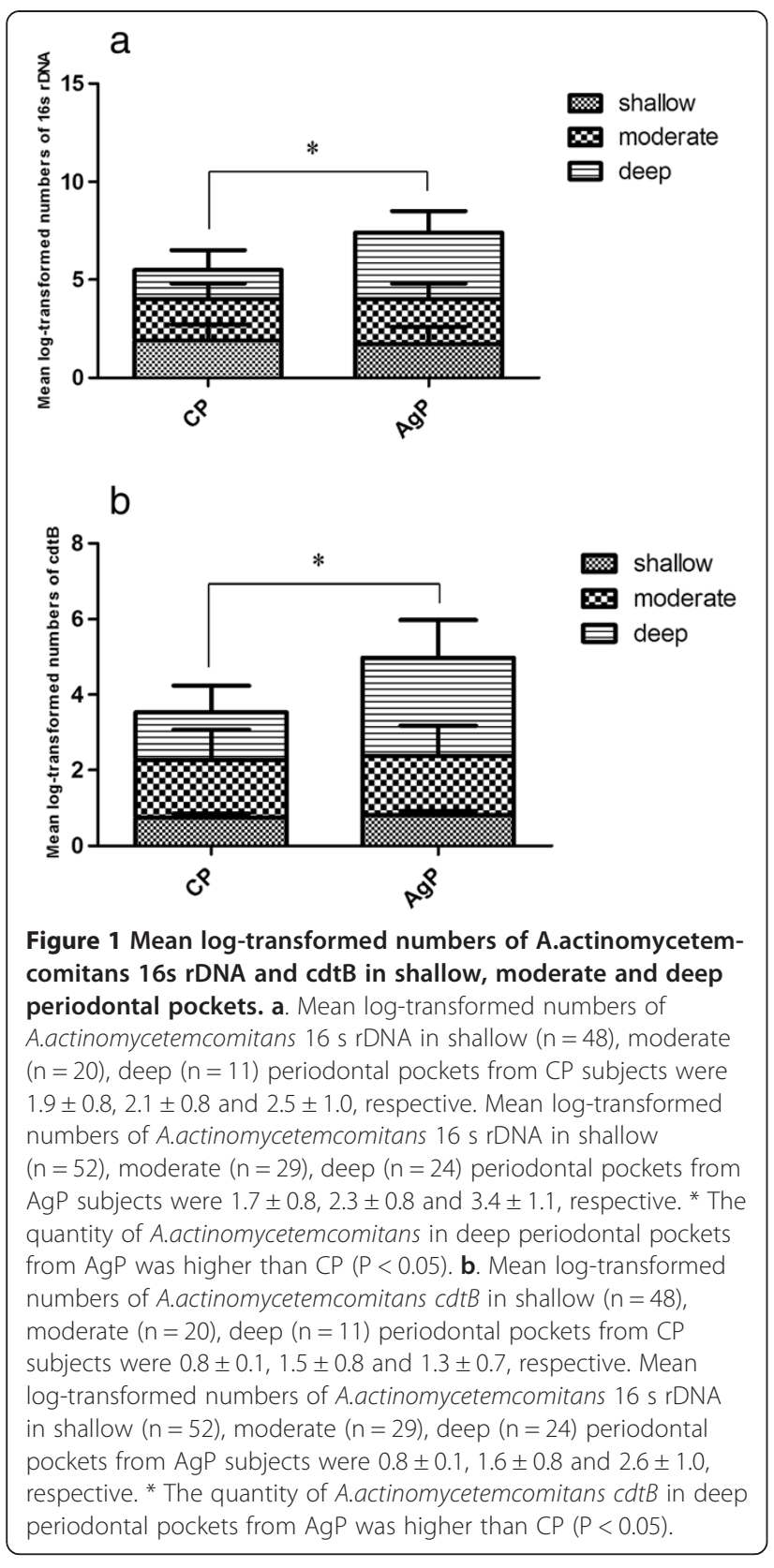

to be quite reliable for detecting the subgingival presence of periodontal pathogens in untreated patients [18]. This technique was based on individual level. While one suffered from periodontitis, aggressive or chronic mode, severity of periodontal disease might differ from site to site. So we evaluated relevance of A.actinomycetemcomitans and its CDT encoding gene with periodontitis stuates base on "site".

The primers chosen for detection of A.actinomycetemcomitans and cdt gene were based on A.actinomycetemcomitans $16 \mathrm{~s}$ rDNA gene and $c d t B$ gene respectively. The $16 \mathrm{~s}$ rDNA gene has been reported to be highly conserved and this pattern for detection of A.actinomycetemcomitans has been well preserved $[19,20]$. Moreover, recent data have shown that $\mathrm{CdtB}$ is the main component and indispensable for the expression of CDT holotoxin activity $[6,8]$, and the sequence of $c d t B$ was also highly conserved among A.actinomycetemcomitans species [21]. Thus, the prevalence of CDT encoding genes was evaluated using $c d t B$ specific primers and probes.

Standard curves were used in this study to evaluate the absolute quantification of A.actinomycetemcomitans and $c d t$ gene in samples. Plasmids containing cloned target sequences were used as standard substances in quantitative PCR, which enabled the measurements more precise and steady compared to using PCR amplicon as standard substances directly [22].

Some studies have examined the prevalence of A.actinomycetemcomitans in some different populations $[4,13,18]$. Our work is the first report on the analysis of both positive rate and absolute quantity of A.actinomycetemcomitans and its $c d t \mathrm{~B}$ gene in Chinese periodontitis patients, and the association of the distribution of A.actinomycetemcomitans and $c d t B$ with various periodontal status.

We found that A.actinomycetemcomitans and its $c d t B$ gene were significantly more prevalent and with higher quantity in samples from patients suffering from AgP or $\mathrm{CP}$ than periodontal healthy subjects, and A.actinomycetemcomitans and its $c d t$ gene were also more prevalent and with higher quantity in deep periodontal pockets than in moderate and shallow periodontal pockets.

Although A.actinomycetemcomitans is linked to the etiology of AgP, this bacterium is also found in subjects who are healthy or have other forms of periodontal disease [8]. Our results showed that only 7.0\% periodontal healthy sites were A.actinomycetemcomitans positive; 92.4\% CP samples and $87.6 \%$ AgP samples exhibited $A$. actinomycetemcomitans positive, demonstrating that the presence of A.actinomycetemcomitans was correlated with periodontitis.

Quantitative data showed that the amount of A.actinomycetemcomitans in $\mathrm{CP}$ and AgP samples were observably higher than in healthy samples, while no difference between CP and AgP. But the amount of $c d t B$ genotype strain of A.actinomycetemcomitans in AgP samples were remarkablly higher than in $\mathrm{CP}$ and healthy samples (Table 3). These data may indicate quantitative results were more suitable to analyse the distribution of A.actinomycetemcomitans and its $c d t B$ genotype strains. The $c d t B$ genotype strain of $A$. actinomycetemcomitans may be more relevant with aggressive periodontitis.

Tan and his coworkers found A.actinomycetemcomitans with the $c d t$ genotype were at a higher frequency from sites obtained from patients diagnosed with aggressive periodontitis [23]. Our study showed the $c d t B$ genotype A.actinomycetemcomitans were at a higher quantity 
from sites obtained from deep pockets. The higher occurrence and amount of this bacterium in samples with severe periodontitis status was not a surprising observation. A.actinomycetemcomitans CDT toxin may be similar to H.ducreyi CDT toxin, which may contribute to the pathogenicity of bacteria at a higher concentration [7]. In vivo studies are still needed to explore the exact pathogenic role of A.actinomycetemcomitans CDT in the future. Our data showed A.actinomycetemcomitans and its $c d t$ genotype strain were prevalent in deep and moderate periodontal pockets. To move forward a single step, quantitative analysis showed $c d t B$ genotype strain of A.actinomycetemcomitans were more prevalent in deep periodontal pockets. The quantities of $c d t$ genotype strain of A.actinomycetemcomitans were correlated with severe forms of periodontitis (CP or AgP). Numerous studies have considered A.actinomycetemcomitans as an important etiological microorganism involved in $\mathrm{AgP}$ [24-26], however, from a new perspective, our data showed that $c d t B$ genotype strain of A.actinomycetemcomitans was mainly found among sites with severe forms of periodontitis. A.actinomycetemcomitans with $c d t B$ genotype may be more virulent to human periodontium.

As expected, none of the A.actinomycetemcomitans $16 \mathrm{~s}$ rDNA negative samples were positive for $c d t B$. This result confirmed that A.actinomycetemcomitans was the exclusive member in the oral microbial flora identified to carry and express the cytolethal distending toxin locus. Besides, there were 5 of healthy samples in our study which were positive for A.actinomycetemcomitans while negative for $c d t$. This may be results of minute quantity of $c d t$ genotype strain of A. actinomycetemcomitans in this 5 subgingival plaque samples, while may be a new supporting proof for the exist of $c d t$-negative genotype strain of A.actinomycetemcomitans in oral cavity.

The $c d t$ gene as well as $l k t A$ (leukotoxin A) of A.actinomycetemcomitans is a single copy gene [21]. However, $16 \mathrm{~s}$ rDNA gene may generally have 4 to 6 copies per cell (e.g., 6 copies for E. coli) [22]. Our results showed that within the same sample the absolute quantity of $A$. actinomycetemcomitans $16 \mathrm{~s}$ rDNA were 1-10 times over that of $c d t B$ gene, which indicated that one periodontal site might be infected with two or even more genotypes of A.actinomycetemcomitans simultaneously. Some genotypes of A.actinomycetemcomitans possess $c d t$ gene, which could express CDT activity; while other genotypes of A.actinomycetemcomitans are cdt-negative, which would be less virulent than $c d t$-positive strains. Yamano [9] reported that 89\% of A.actinomycetemcomitans strains possessed the $c d t$ gene. Another study [4] discovered that $86 \%$ of A.actinomycetemcomitans isolates presented complete operon of $c d t$ gene and its characteristic cytotoxic activity. Tan and his coworkers showed a close association between AgP and $c d t$-positive genotype A.actinomycetemcomitans strains [23]. These findings suggested that not all the strains of A.actinomycetemcomitans possessed $c d t$ gene, in other words, not every A.actinomycetemcomitans strains presented cytotoxic CDT activity. Similar to A.actinomycetemcomitans strains, Campylobacter spp., C.jejuni, H.ducreyi and other CDT-producing bacteria don't express CDT activity or contain all of the $c d t A B C$ genes in all strains [4].

\section{Conclusion}

Our study investigated the prevalence and distribution of A.actinomycetemcomitans and its $c d t$ gene in subgingival plaque from Chinese periodontitis patients. The significantly increased quantities of $c d t$-positive genotype A.actinomycetemcomitans were found in $\mathrm{AgP}$ periodontal sites and in deep pockets of both $\mathrm{CP}$ and AgP patients, which indicated that $c d t$ gene might be a potential virulenceassociated gene involved in the pathogenesis of $\mathrm{AgP}$ and severe periodontal destruction. Our results suggested the importance of obtaining both A.actinomycetemcomitans titer and genotype identification in periodontitis microbiological diagnosis. Extensive studies are necessary for providing more information about the molecular pathophysiological role of A.actinomycetemcomitans and its CDT.

\section{Transparency declaration}

This study is supported by grants from the National Natural Science Foundation of China (Grant No. 81170962), Project of Science and Technology Department of Jiangsu Province (Grant No. BK2011763) and Project Funded by the Priority Academic Program Development of Jiangsu Higher Education Institutions (Grant No. PAPD20112013).

\section{Competing interests}

The authors declare that they have no competing interests.

\section{Authors' contributions}

XW and LL carried out the samples collection, periodontal examination, participated in the DNA extraction and Real-time PCR and drafted the manuscript. YG and HC participated in the sequence alignment. YX, YS participated in the design of the study. MY participated in its design and coordination and helped to draft the manuscript. All authors read and approved the final manuscript.

\section{Acknowledgements}

We thank Dr. Zhibin Hu and Dr. Guangfu Jin (Department of Epidemiology and Biostatistics, School of Public Health, Nanjing Medical University) for their constructive suggestions and excellent technical assistance.

Received: 19 January 2014 Accepted: 27 March 2014 Published: 13 April 2014

\section{References}

1. Sugai M, Kawamoto $T$, Pérès $S Y$, Ueno $Y$, Komatsuzawa $H$, Fujiwara $T$, Kurihara H, Suginaka H, Oswald E: The cell cycle-specific growth-inhibitory factor produced by Actinobacillus actinomycetemcomitans is a cytolethal distending toxin. Infect Immun 1998, 66:5008-5019. 
2. Asakura M, Samosornsuk W, Taguchi M, Kobayashi K, Misawa N, Kusumoto M, Nishimura K, Matsuhisa A, Yamasaki S: Comparative analysis of cytolethal distending toxin (cdt) genes among Campylobacter jejuni, $C$. coli and C. fetus strains. Microb Pathog 2007, 42:174-183.

3. Fox JG, Rogers AB, Whary MT, Ge Z, Taylor NS, Xu S, Horwitz BH, Erdman SE: Gastroenteritis in NF-kappaB-deficient mice is produced with wild-type Camplyobacter jejuni but not with C. jejuni lacking cytolethal distending toxin despite persistent colonization with both strains. Infect Immun 2004, 72:1116-1125.

4. Ahmed HJ, Svensson LA, Cope LD, Latimer JL, Hansen EJ, Ahlman K, Bayat-Turk J, Klamer D, Lagergård T: Prevalence of cdtABC genes encoding cytolethal distending toxin among Haemophilus ducreyi and Actinobacillus actinomycetemcomitans strains. J Med Microbiol 2001, 50:860-864.

5. Haghjoo E, Galán JE: Salmonella typhi encodes a functional cytolethal distending toxin that is delivered into host cells by a bacterialinternalization pathway. Proc Natl Acad Sci U S A 2004, 101:4614-4619.

6. Lara-Tejero M, Galán JE: A bacterial toxin that controls cell cycle progression as a deoxyribonuclease I-like protein. Science 2000, 290:354-357.

7. Elwell CA, Dreyfus LA: DNase I homologous residues in CdtB are critical for cytolethal distending toxin-mediated cell cycle arrest. Mol Microbiol 2000, 37:952-963. Ge Z, Schauer DB, Fox JG.: In vivo virulence properties of bacterial cytolethal-distending toxin. Cell Microbiol 2008, 10:1599-1607.

8. Fabris AS, DiRienzo JM, Wikstrom M, Mayer MP: Detection of cytolethal distending toxin activity and cdt genes in Actinobacillus actinomycetemcomitans isolates from geographically diverse populations. J Oral Microbiol Immunol 2002, 17:231-238.

9. Yamano $R$, Ohara M, Nishikubo S, Fujiwara T, Kawamoto T, Ueno $Y$, Komatsuzawa H, Okuda K, Kurihara H, Suginaka H, Oswald E, Tanne K, Sugai M: Prevalence of cytolethal distending toxin production in periodontopathogenic bacteria. J Clin Microbiol 2003, 41:1391-1398.

10. Kawamoto D, Ando ES, Longo PL, Nunes AC, Wikström M, Mayer MP: Genetic diversity and toxic activity of Aggregatibacter actinomycetemcomitans isolates. Oral Microbiol Immunol 2009, 24:493-501.

11. Armitage GC: Development of a classification system for periodontal diseases and conditions. Ann Periodontol 1999, 4:1-6.

12. American Academy of Periodontology: Parameter on progressive periodontitis. J Periodontol 2000, 71:867-869.

13. Meng S, Zhao L, Yang H, Wu Y, Ouyang Y: Prevalence of Actinobacillus actinomycetemcomitans in Chinese chronic periodontitis patients and periodontally healthy adults. Quintessence Int 2009, 40:53-60.

14. Cortelli SC, Costa FO, Kawai T, Aquino DR, Franco GC, Ohara K, Roman-Torres CV, Cortelli JR: Diminished treatment response of periodontally diseased patients infected with the JP2 clone of Aggregatibacter (Actinobacillus) actinomycetemcomitans. J Clin Microbiol 2009, 47:2018-2025.

15. Jervøe-Storm PM, Alahdab H, Koltzscher M, Fimmers R, Jepsen S: Comparison of curet and paper point sampling of subgingival bacteria as analyzed by real-time polymerase chain reaction. J Periodontol 2007, 78:909-917.

16. Krigar DM, Kaltschmitt J, Krieger JK, Eickholz P: Two subgingival plaque sampling strategies used with RNA-probes. J Periodontol 2007, 78:72-78.

17. Nonnenmacher C, Dalpke A, Mutters R, Heeg K: Quantitative detection of periodontopathogens by real-time PCR. J Microbiol Methods 2004, 59:117-125.

18. Cortelli JR, Roman-Torres CV, Aquino DR, Franco GC, Costa FO, Cortelli SC: Occurrence of Aggregatibacter actinomycetemcomitans in Brazilians with chronic periodontitis. Braz Oral Res 2010, 24:217-223.

19. Turenne CY, Tschetter $L$, Wolfe J, Kabani A: Necessity of quality-controlled 16S rRNA gene sequence databases: identifying nontuberculous Mycobacterium species. J Clin Microbiol 2001, 39:3637-3648.

20. Yoshida A, Suzuki N, Nakano Y, Oho T, Kawada M, Koga T: Development of a 5 ' fluorogenic nuclease-based real-time PCR assay for quantitative detection of Actinobacillus actinomycetemcomitans and Porphyromonas gingivalis. J Clin Microbiol 2003, 41:863-866.

21. Morillo JM, Lau L, Sanz M, Herrera D, Martín C, Silva A: Quantitative real-time PCR based on single copy gene sequence for detection of Actinobacillus actinomycetemcomitans and Porphyromonas gingivalis. J Periodontal Res 2003, 38:518-524.

22. Doungudomdacha S, Rawlinson A, Douglas CW: Enumeration of Porphyromonas gingivalis, Prevotella intermedia and Actinobacillus actinomycetemcomitans in subgingival plaque samples by a quantitative-competitive PCR method. J Med Microbiol 2000, 49:861-874.

23. Tan KS, Song KP, Ong G: Cytolethal distending toxin of Actinobacillus actinomycetemcomitans.:Occurrence and association with periodontal disease. J Periodontal Res 2002, 37:268-272.

24. Casarin RC, Ribeiro Edel P, Mariano FS, Nociti FH Jr, Casati MZ, Gonçalves RB: Levels of aggregatibacter actinomycetemcomitans, porphyromonas gingivalis, inflammatory cytokines and species-specific immunoglobulin $\mathrm{G}$ in generalized aggressive and chronic periodontitis. J Periodontal Res 2010, 45:635-642.

25. Kaplan JB, Schreiner HC, Furgang D, Fine DH: Population structure and genetic diversity of Actinobacillus actinomycetemcomitans strains isolated from localized juvenile periodontitis patients. J Clin Microbiol 2002, 40:1181-1187.

26. Schacher B, Baron F, Rossberg M, Wohlfeil M, Arndt R, Eickholz P: Aggregatibacter actinomycetemcomitans as indicator for aggressive periodontitis by two analyzing strategies. J Clin Periodontol 2007, 34:566-573.

doi:10.1186/1472-6831-14-37

Cite this article as: Wang et al:: Prevalence and distribution of

Aggregatibacter actinomycetemcomitans and its $c d t B$ gene in subgingival plaque of Chinese periodontitis patients. BMC Oral Health 2014 14:37.

\section{Submit your next manuscript to BioMed Central and take full advantage of:}

- Convenient online submission

- Thorough peer review

- No space constraints or color figure charges

- Immediate publication on acceptance

- Inclusion in PubMed, CAS, Scopus and Google Scholar

- Research which is freely available for redistribution 